\title{
Evolution of the Chinese Industry-University-Research Collaborative Innovation System
}

\author{
Jianyu Zhao ${ }^{1,2}$ and Guangdong $\mathrm{Wu}^{3}$ \\ ${ }^{1}$ School of Economics and Management, Harbin Engineering University, Heilongjiang, Harbin 150001, China \\ ${ }^{2}$ School of Management, Harbin Institute of Technology, Heilongjiang, Harbin 150001, China \\ ${ }^{3}$ School of Tourism and Urban Management, Jiangxi University of Finance and Economics, Nanchang 330013, China
}

Correspondence should be addressed to Jianyu Zhao; jianyu64@sina.com

Received 28 November 2016; Revised 19 March 2017; Accepted 29 March 2017; Published 9 April 2017

Academic Editor: Katarzyna Musial

Copyright (C) 2017 Jianyu Zhao and Guangdong Wu. This is an open access article distributed under the Creative Commons Attribution License, which permits unrestricted use, distribution, and reproduction in any medium, provided the original work is properly cited.

\begin{abstract}
The goal of this study was to reveal the mechanism of the Chinese industry-university-research collaborative innovation (IURCI) and interactions between the elements in the system and find issues that exist in the collaborative innovation process. Based on the theoretical perspective of innovation and complexity science, we summarized the elements of the IURCI as innovation capability, research and development $(\mathrm{R} \& \mathrm{D})$ configuration, and knowledge transfer and established a theoretical model to describe the evolution of the IURCI system. We used simulation technology to determine the interactions among variables and the evolution trend of the system. The results showed that the R\&D configuration can promote the evolution of innovation capability and knowledge transfer and that innovation capacity is the current dominant factor in the evolution of the Chinese IURCI system and is highly positively correlated with R\&D configuration. The evolutionary trend of knowledge transfer was gentler, and its contribution to the evolution of the Chinese IURCI system was less than that of R\&D configuration. When innovation, R\&D configuration, and knowledge transfer are relatively balanced, the collaborative innovation system can achieve high speed and stable evolution.
\end{abstract}

\section{Introduction}

Innovation is an important stimulator of economic development and is also a key element in the global competitiveness of the country. As the world's second largest economy, China has made great progress along the road of independent innovation, research, and development investment, and the number of academic achievements and patents has been ranked at the top in the world. But in spite of this progress, there is a disconnection between the economy and technology in the process of innovation in China. On the one hand, the Global Competitiveness Report developed by the World Economic Forum according to the Global Competitiveness Index (GCI) showed that China's technological readiness for innovation (ranked at \#88) has seriously hampered the country's competitiveness ranking, indicating that the innovation capability of core technology in Chinese enterprises is still relatively backward, failing to form an innovation-driven development model, and many industry's core technologies with significantly shorter cycles of innovation are still heavily dependent on foreign countries. On the other hand, the conversion rate of technological achievements has been low for a long time in Chinese universities and research institutions; therefore, higher education training is lagging behind (ranked \#62). Universities and research institutions cannot effectively meet the knowledge requirements for innovation, which is also an important factor that has led to delays in the Chinese innovation system. The Organization for Economic Co-operation and Development's China Innovation Policy Research Report pointed out that coordination and integration in China's innovation system is not perfect, and the synergy between constituent subjects in the system is low. Compared with developed countries, Chinese enterprises not only lack the R\&D capabilities of core technology, but also the effects of knowledge accumulation are relatively poor. Enterprises tend to be more cost-oriented and lack the motivation to carry out and use public research achievements. Meanwhile, enterprises, universities, and research 
institutes rarely share innovation resources, most types of technology transfer are carried out under the guidance of government, and universities and research institutions do not take the initiative to understand the technology needs of industry. These problems have seriously hampered knowledge spillover in the Chinese innovation system and have become an obstacle that China must overcome to build an innovation-driven country through independent innovation.

An effective measure to solve the above problem is to establish a practical and effective Chinese cooperative research innovation system, thus contributing to the rapid transformation of public scientific and technological achievements of Chinese enterprises and universities as well as research institutions, and to promote scientific research in Chinese universities and institutes that feeds the demand for industrial innovation, thus allowing technological development and industrial development to move forward together. Research on the evolution of the Chinese industry-university-research (IUR) collaborative innovation (IURCI) system can help identify the interactions between the elements of Chinese IURCI systems and, through identifying problems in the process of collaborative innovation, can help Chinese enterprises and universities as well as research institutions emerge from the knowledge dilemma of collaborative innovation. This study therefore has theoretical and practical value for enhancing collaborative innovation efficiency and promoting IURCI development in China.

In contrast to the past static perspective, we established an evolutionary logistics/dynamics equation to describe the research collaborative innovation system in China, using relevant methods from game theory to solve it. On this basis, we collected indices and data that have influenced Chinese IURCI from 2005 to 2014, simulated the evolution morphology of related variables by MATLAB software, analyzed the interactions between elements and dynamic evolution, and demonstrated in detail the evolution mechanism of the research innovation system in China. In this study, while revealing the essence of Chinese IURCI, we have tried to establish a new research framework and explain 2 issues: first, there are different degrees of interaction among variables in the Chinese IURCI system, with different levels of contribution to the evolution of a collaborative innovation system and, second, when the default initial value of evolution changes, an evolutionary trend develops among the variables.

In Section 2 of this paper, we describe our analysis of the constituent elements of the IURCI system and the synergy principle. On this basis, in Section 3, we describe how we established an IURCI system evolution model with a focus on innovation capacity, R\&D configuration, and knowledge transfer, and conducted derivation and analysis. In Section 4, we conducted a simulation using actual data of relevant parameters and analyzed the results. Finally, in the conclusion, we discuss the innovation and contribution of research achievements and propose the main direction for future research.

\section{Theory}

IURCI refers to enterprises, universities, and research institutes, 3 main users of innovation to expand their resources and capabilities, which jointly develop technology innovation activities under the support of government, science and technology intermediary service agencies, financial institutions, and other relevant organizations $[1,2]$. In the process of IURCI, enterprises, universities, and research institutes convert science and technology into practical, productive forces for the purpose of innovation, based on a clear division of functions, through complex nonlinear interactions. This realizes mutual benefits between enterprises and universities as well as research institutes and produces a synergistic innovation impact that each factor cannot achieve alone [3]. Canhoto et al. [4] believe that the essence of collaboration is the complementary use of resources and capabilities between competitive enterprises and universities as well as research institutions. The advantages of enterprises include the rapid commercialization of technology, relatively adequate innovation funding, suitable production and test equipment and sites, and market information and marketing experience, and their needs for innovation are in basic principles of knowledge and in scientific as well as technical human resources [5-7]. The advantages of universities and research institutions are theoretical research, professionals, scientific equipment, knowledge and technical information, and research methods and experience, and their needs for innovation are resource support and practical information [8-10]. The needs of enterprises for innovation in knowledge resources and the needs of universities and research institutions for spreading of scientific knowledge and practice demand constitute the IURCI system based on a retrieval mechanism and allocation rule for noncompetitive interests [11-13].

Improving collaborative innovation system performance is a strategic goal, and, from the 1980s up to the present, there have been theories such as the innovation systems theory [14-16], triple helix [17-20], and open innovation theory [2124] which have discussed the elements and principles of an IURCI system at different levels $[25,26]$. The innovation system theory is that, in the process of collaborative innovation and research, knowledge reformation is the key to enhance collaborative innovation performance [27-29]. This reformation mainly relies on the resource investment level and the specificity of the R\&D configuration and on knowledge accessibility as well as access of universities and research institutions to enterprises. In fact, since technological innovation has become the key to business competition, more and more enterprises have started to pursue the development of industrial common technology or cutting-edge technologies. This development, on the one hand, stems from the enhanced ability of an R\&D configuration to promote an innovation system, and, on the other hand, it results from knowledge flowing from the innovation platform of enterprises as they cooperate with universities and research institutions, that is, knowledge transfer within the IURCI system [30,31]. Using resource dependence theory and knowledge management theory, the microperspective analysis of the Triple Helix Model found that the nature of evolution of the IURCI system 
involves nonlinear interactions among knowledge transfer, $\mathrm{R} \& \mathrm{D}$ configuration, and innovation capability [32-34]. Further, the open innovation theory $[35,36]$, which looked at the aspects of fitness and openness between subjects, confirmed that $\mathrm{R} \& \mathrm{D}$ resource configuration is the basic premise for IURCI system evolution, and knowledge transfer is, within the constraints of transaction cost law, in the common interests of companies and universities well as research institutions. We therefore believe that the evolution of the IURCI system depends on innovation, R\&D configuration, and knowledge transfer, and the interactions among the 3 not only surpass the general innovation paradigm of evolution in previous evolutionary economics but also represent the core element to decide and change collaborative innovation system performance.

IURCI is a complex social system, and the interactions among those constituent elements are the premise to enhance collaborative innovation performance. Innovation, R\&D configuration, and knowledge transfer become the key to determine the evolution of a collaborative innovation system and determine its performance. Therefore, to analyze the IURCI mechanism, we use the theory as well as method of Synthetics [37], which illustrates the interactions among elements in complex system and establish the logistic equation which analyzes and explains the interactions among innovation capacity, R\&D configuration, and knowledge transfer. We need to demonstrate precisely and comprehensively the interactions among the 3 elements in the collaborative innovation process, innovation, $\mathrm{R} \& \mathrm{D}$ configuration, and knowledge transfer, thus revealing the nature of IURCI.

\section{Model}

\subsection{Model Establishment}

3.1.1. Logistic Evolution Equation of Innovation Capacity. Faced with the fact of tight resources, in order to improve innovation performance, universities and industry are bound to demand cooperation. Knowledge transfer and flow in the IURCI system eventually lead to improved innovation capabilities in the system. Meanwhile, the IURCI system, in order to achieve higher innovation performance, will continue to increase efforts to improve $\mathrm{R} \& \mathrm{D}$ configuration, which to some extent will promote innovation capacity, and thereby the evolution equation of innovation capacity is written as follows:

$$
\frac{d n_{1}}{d t}=\alpha_{1} n_{1}+\beta_{1} n_{1} n_{3}+\gamma_{1} n_{2}
$$

In formula (1), $\alpha_{1}$ represents the influence of coefficient of innovation $n_{1}$ itself and $\beta_{1} n_{3}$ stands for the influence factor of $R \& D$ configuration on innovation capacity, namely, the impact of increasing allocation of $\mathrm{R} \& \mathrm{D}$ configuration on innovation capacity. Under normal circumstances $\beta_{1}>$ $0, \gamma_{1}$ is the influence factor of knowledge transfer and represents the interaction between knowledge transfer and $\mathrm{R} \& \mathrm{D}$ configuration.
3.1.2. Logistic Evolution Equation of R\&D Configuration. Improved innovation capacity of the IURCI system will appeal to the willingness of businesses, universities, and research institutes to improve R\&D configuration; therefore, innovative ability $n_{1}$ is also an influencing factor of R\&D configurations $n_{2}$. Meanwhile, in the process of knowledge transfer in the IURCI system, enterprises will continuously increase resources investment in R\&D in order to continuously create and achieve high-value heterogeneity knowledge, and we can thereby establish the evolution equation of R\&D configuration as follows:

$$
\frac{d n_{2}}{d t}=-\alpha_{2} n_{2}+\beta_{2} n_{1} n_{2}+\gamma_{2} n_{3} .
$$

In formula (2), $-\alpha_{2}$ represents the influence coefficient of the $R \& D$ configuration itself. $\beta_{2} n_{1}$ represents the influence coefficient of innovation capability on R\&D configuration. Because there is positive feedback between R\&D configuration $n_{2}$ and innovation capability $n_{1}$, the coefficient $\beta_{2}$ is also positive. Finally, $\gamma_{2}$ represents the impact size of knowledge transfer on R\&D configuration.

3.1.3. Logistic Evolution Equation of Knowledge Transfer. Knowledge transfer between enterprises and universities as well as research institutions can have an impact on the innovation capacity in the IURCI system. Meanwhile, as the $R \& D$ configuration increases, the needs of the IURCI system for innovation and new knowledge continuously increase, thereby facilitating improvement in the knowledge transfer capability of the IURCI system. This demonstrated that there is a positive correlation between the 2 variables, knowledge transfer and R\&D configuration, and thereby we can establish the evolution equation of knowledge transfer; thus,

$$
\frac{d n_{3}}{d t}=\alpha_{3} n_{3}+\beta_{3} n_{2}
$$

In formula (3), $\alpha_{3}$ represents the influence coefficient of knowledge transfer itself and $\beta_{3}$ represents the impact degree of R\&D configuration $n_{2}$ on knowledge transfer capacity.

Using innovation capacity, R\&D configuration, and knowledge transfer of IUR as the 3 variables and using a simultaneous logistics evolution equation, we obtained a dynamic evolution model as follows:

$$
\begin{aligned}
& \frac{d n_{1}}{d t}=\alpha_{1} n_{1}+\beta_{1} n_{1} n_{3}+\gamma_{1} n_{2}, \\
& \frac{d n_{2}}{d t}=-\alpha_{2} n_{2}+\beta_{2} n_{1} n_{2}+\gamma_{2} n_{3}, \\
& \frac{d n_{3}}{d t}=\alpha_{3} n_{3}+\beta_{3} n_{2} .
\end{aligned}
$$

In formula (4), $n_{1}, n_{2}, n_{3}$ are constants, and the definitions of $\alpha, \beta, \gamma$ are as follows.

$\alpha=\sqrt[i]{\prod_{i=1}^{p} \alpha_{i}}(i=1,2,3, \ldots, p)$ is an adjustment parameter of the state variable $n_{1}$, corresponding to an innovation capability index, wherein $\alpha_{i}$ is the resulting parameter after 
conversion of each index in the evaluation system, wherein $\alpha_{i}$ is the resulting parameter after conversion of each index in innovation capacity evaluation system.

$$
\beta=\sqrt[i]{\prod_{i=1}^{p} \beta_{i}}(i=1,2,3, \ldots, p) \text { is an adjustment }
$$
parameter of the state variable $n_{2}$, corresponding to the $\mathrm{R} \& \mathrm{D}$ configuration index, wherein $\beta_{i}$ is the resulting parameter after conversion of each index in $\mathrm{R} \& \mathrm{D}$ configuration evaluation system.

$$
\gamma=\sqrt[i]{\prod_{i=1}^{p} \gamma_{i}}(i=1,2,3, \ldots, p) \text { is an adjustment parame- }
$$
ter of the state variable $n_{3}$, corresponding to the knowledge transfer index, wherein $\gamma_{i}$ is the resulting parameter after conversion of each index in knowledge transfer evaluation system.

\subsection{Model Analysis}

3.2.1. Linearization. According to Krasovskii's method [38], we used a gradient vector matrix in the operation system to solve the stable solution of evolution model, wherein the systematic coefficient matrix was solved using the Taylor Formula [39]. After performing Taylor, omitting higher-order terms of a second and higher order, we then obtained the linearized coefficient matrix $M$ (Jacobian matrix) as follows:

$$
M=\nabla F=\left[\begin{array}{cccc}
\frac{\partial f_{1}(X)}{\partial x_{1}} & \cdots & \cdots & \frac{\partial f_{1}(X)}{\partial x_{n}} \\
\frac{\partial f_{2}(X)}{\partial x_{1}} & \ddots & \cdots & \vdots \\
\vdots & \vdots & & \vdots \\
\frac{\partial f_{n}(X)}{\partial x_{1}} & \cdots & \cdots & \frac{\partial f_{n}(X)}{\partial x_{n}}
\end{array}\right] .
$$

Thus, according to Krasovskii's method, we rewrite formula (4) in the form of a matrix multiplication $\dot{X}=M \cdot X$ and obtain the following:

$$
\left[\begin{array}{c}
\dot{x}_{1} \\
\vdots \\
\dot{x}_{n}
\end{array}\right]=\left[\begin{array}{ccc}
\frac{\partial f_{1}(X)}{\partial x_{1}} & \cdots & \frac{\partial f_{1}(X)}{\partial x_{n}} \\
\vdots & \ddots & \vdots \\
\frac{\partial f_{n}(X)}{\partial x_{1}} & \cdots & \frac{\partial f_{n}(X)}{\partial x_{n}}
\end{array}\right]\left[\begin{array}{c}
x_{1} \\
\vdots \\
x_{n}
\end{array}\right] .
$$

Formula (6) represents the initial state of the IURCI system with 0 input. We can use linear system theory to obtain the time domain expression of state variable $X$, that is, the solution of system variable $X$ after linearization of the evolution equation.

For evolution equations, we solved using the Laplace transformation [40], and formula (4) was converted to the following:

$$
\begin{aligned}
s X(s)-X_{0} & =M \cdot X(s), \\
(s I-M) X(s) & =X_{0} .
\end{aligned}
$$

Laplace transformation of $X$ is obtained as follows:

$$
X(s)=(s I-M)^{-1} X_{0} .
$$

Thus we obtained an expression of the time domain of $X$ as follows:

$$
X=L^{-1}\left((s I-M)^{-1} X_{0}\right)
$$

In formula (9), $s$ is a pull complex symbol, $X_{0}$ represents the initial state of the matrix, $X(s)$ is the pull transformation of $X(t),(s I-M)^{-1}$ represents the inverse matrix of matrix $(s I-M)$, and $L^{-1}$ is the anti-Laplace transformation.

3.2.2. Stable Solution. According to the linearization results, formula (4) is solved to obtain the Jacobian matrix as follows:

$$
\begin{aligned}
J & =\left[\begin{array}{lll}
\frac{\partial f_{1}}{\partial n_{1}} & \frac{\partial f_{1}}{\partial n_{2}} & \frac{\partial f_{1}}{\partial n_{3}} \\
\frac{\partial f_{2}}{\partial n_{1}} & \frac{\partial f_{2}}{\partial n_{2}} & \frac{\partial f_{2}}{\partial n_{3}} \\
\frac{\partial f_{3}}{\partial n_{1}} & \frac{\partial f_{3}}{\partial n_{2}} & \frac{\partial f_{3}}{\partial n_{3}}
\end{array}\right] \\
= & {\left[\begin{array}{ccc}
\alpha_{1}+\beta_{1} n_{3} & \gamma_{1} & \beta_{1} n_{1} \\
\beta_{2} n_{2} & -\alpha_{2}+\beta_{2} n_{1} & \gamma_{2} \\
0 & \beta_{3} & \alpha_{3}
\end{array}\right] }
\end{aligned}
$$

to obtain

$$
|J|=\left|\begin{array}{ccc}
\alpha_{1}+\beta_{1} n_{3} & \gamma_{1} & \beta_{1} n_{1} \\
\beta_{2} n_{2} & -\alpha_{2}+\beta_{2} n_{1} & \gamma_{2} \\
0 & \beta_{3} & \alpha_{3}
\end{array}\right| .
$$

Meanwhile, according to the result of formula (11) of Jacobian matrix, we set $d n_{1} / d t=0 ; d n_{2} / d t=0 ; d n_{3} / d t=0$, and formula (12) was obtained as follows:

$$
\begin{aligned}
\alpha_{1} n_{1}+\beta_{1} n_{1} n_{3}+\gamma_{1} n_{2} & =0, \\
-\alpha_{2} n_{2}+\beta_{2} n_{1} n_{2}+\gamma_{2} n_{3} & =0, \\
\alpha_{3} n_{3}+\beta_{3} n_{2} & =0 .
\end{aligned}
$$

According to this equation, we use Routh-Hurwitz stability criterion [41] and the stable solution of complex system to solve formula (12), so that a partial equilibrium point can be obtained as follows:

$$
\begin{aligned}
& A(0,0,0) \\
& B\left(\frac{\alpha_{2} \alpha_{3}+\beta_{3} \gamma_{2}}{\alpha_{3} \beta_{2}}, \frac{\alpha_{1} \alpha_{2} \alpha_{3}^{2}+\alpha_{1} \alpha_{3} \beta_{2} \gamma_{2}}{\alpha_{3}^{2} \beta_{2} \gamma_{1}-\alpha_{2} \alpha_{3} \beta_{1} \beta_{3}-\beta_{1} \beta_{3}^{2} \gamma_{2}},\right. \\
& \left.\quad \frac{\alpha_{1} \alpha_{2} \alpha_{3} \beta_{3}+\alpha_{1} \beta_{2} \beta_{3} \gamma_{2}}{\alpha_{2} \alpha_{3} \beta_{1} \beta_{3}+\beta_{1} \beta_{3}^{2} \gamma_{2}-\alpha_{3}^{2} \beta_{2} \gamma_{1}}\right) .
\end{aligned}
$$

Bringing the equilibrium points $A$ and $B$, respectively, into the Jacobian matrix, and judging equilibrium according 
to the trace and matrix determinant symbols of the Jacobian matrix, we obtained the following:

$$
\operatorname{tr}(J)=\alpha_{3}+\beta_{2} n_{1}+\beta_{1} n_{1}-\alpha_{1}-\alpha_{2} .
$$

For equilibrium point $A$,

$$
\operatorname{tr}(J)=\alpha_{3}-\alpha_{1}-\alpha_{2}
$$

$$
\begin{aligned}
\operatorname{tr}(J) & =\alpha_{3}+\alpha_{1}+\frac{\beta_{3} \gamma_{2}}{\alpha_{3}}+\frac{\alpha_{1} \alpha_{2} \alpha_{3} \beta_{1} \beta_{3}+\alpha_{1} \beta_{1} \beta_{2} \beta_{3} \gamma_{2}}{\alpha_{2} \alpha_{3} \beta_{1} \beta_{3}+\beta_{1} \beta_{3}^{2} \gamma_{2}-\alpha_{3}^{2} \beta_{2} \gamma_{1}} \\
|J| & \left|\begin{array}{ccc}
\frac{2 \alpha_{1} \alpha_{2} \alpha_{3} \beta_{1} \beta_{3}+\alpha_{1} \beta_{1} \beta_{2} \beta_{3} \gamma_{2}+\alpha_{1} \beta_{1} \beta_{3}^{2} \gamma_{2}-\alpha_{1} \alpha_{3}^{2} \beta_{2} \gamma_{1}}{\alpha_{2} \alpha_{3} \beta_{1} \beta_{3}+\beta_{1} \beta_{3}^{2} \gamma_{2}-\alpha_{3}^{2} \beta_{2} \gamma_{1}} & \gamma_{1} & \frac{\alpha_{2} \alpha_{3} \beta_{1}+\beta_{1} \beta_{3} \gamma_{2}}{\alpha_{3} \beta_{2}} \\
\frac{\alpha_{1} \alpha_{2} \alpha_{3}^{2} \beta_{2}+\alpha_{1} \alpha_{3} \beta_{2}^{2} \gamma_{2}}{\alpha_{3}^{2} \beta_{2} \gamma_{1}-\alpha_{2} \alpha_{3} \beta_{1} \beta_{3}-\beta_{1} \beta_{3}^{2} \gamma_{2}} & \frac{\beta_{3} \gamma_{2}}{\alpha_{3}} & \gamma_{2} \\
0 & \beta_{3} & \alpha_{3}
\end{array}\right| .
\end{aligned}
$$

$$
|J|=\left|\begin{array}{ccc}
\alpha_{1} & \gamma_{1} & 0 \\
0 & -\alpha_{2} & \gamma_{2} \\
0 & \beta_{3} & \alpha_{3}
\end{array}\right| .
$$

For equilibrium point $B$,
Each point value of point $A$ is 0 , representing the initial steady state; thus initial state $n_{1}^{0}$ is substituted into expressions for $n_{1}$. It can be understood that since the initial value is set to 0 , the system has been in a steady state, and the value is always 0 . Since there are nonlinear interactions among the 3 variables, innovation capability, R\&D configuration, and knowledge transfer in IURCI systems, these caused a new stable state $B$ in the system. A systematic state change from $A$ to $B$ represents the evolution of the IURCI system. Interactions among the variables and evolution law will determine the outcome of system evolution.

\section{Simulation}

4.1. Parameter Value. To find existing insufficiency in the Chinese IURCI system, we set specific values of parameters, calculated the coefficient and Jacobian matrix of the model, simulated it using MATLAB, and drew an evolution chart of the 3 variables in the IURCI system. In contrast to a previous capability evaluation in the IURCI system, we measured values of the original control parameters $\alpha, \beta$, and $\gamma$ of innovation capacity, R\&D configuration, and knowledge transfer through establishment of an index system. Because innovation capacity represents the presence of IURCI system evolution, we considered relevant content such as innovation effects and innovation gains in the index selection. R\&D configuration represents a resource configuration in the IURCI system, so index selection involved funding, personnel, institutional settings, and other aspects. Knowledge transfer represents knowledge flow between enterprises and universities as well as research institutions in IURCI systems, so indicator selection was based on the state of cooperation as the core. We learned from the studies of $[18,26,31]$ and other scholars to improve our procedures and ultimately arrived at the indicators shown in Table 1.

In Table 1, each index value was obtained from the China Statistical Yearbook, the China Statistical Yearbook On Science and Technology, the China S \& T Paper Statistics and Analysis, the China Industry Economy Statistical Yearbook, Statistics Yearbook On Science And Technology Activities of Industrial Enterprise, the Annual Report of Regional Innovation Capability of China, the NERI INDEX of Marketization of China's Provinces Report, and the SME Technology Innovation Fund. Related public data from 2005 to 2014 were taken from the statistical yearbooks $(2015,2016$ information was not disclosed) to give the final parameter values through data standardization.

According to the solving method [37] of $\alpha, \beta, \gamma$ in formula (4), we bring in the data of 2005-2014 from Table 1 and get the parameter values in Table 2.

Table 2 shows the parameter values of the evolution model, and the values of $\alpha_{1}, \beta_{1}, \gamma_{1}$ were calculated from the specific data in the index systems shown in Table 1. In order to obtain the final parameter values of the evolutionary model, we averaged values for 2005-2014 and obtained Table 3.

We substituted values for the 9 parameters into the Jacobian matrix, calculated the determinant and trace of the matrix corresponding to the Jacobian matrix, and analyzed steady-state values of $A$ and $B$ by judging the determinant and trace symbols.

4.2. Tests and Analysis. Using the Jacobian matrix as the coefficient matrix of the equation, the initial state matrix of the differential equation is $\left[n_{1}^{0}, n_{2}^{0}, n_{3}^{0}\right]$, wherein $n_{1}^{0}, n_{2}^{0}, n_{3}^{0}$ represent the initial values of the 3 variables, innovation, $R \& D$ configuration, and knowledge transfer, respectively. Point $A$ represents the initial state, and the initial state of the system is 0 , such that $N^{0}=[0,0,0]$; therefore, substituting this into the expression, we obtained the solution for the expression of innovation capacity of 0 , that is, $n_{1}^{0}, n_{2}^{0}, n_{3}^{0}=[0,0,0]$, and the output response curve is 0 , which indicates the initial state (Figure 1).

In all the figures (Figures 1-8), the $x$-axis represents the input of three elements, whereas the $y$-axis represents evolution performance. For different values of the initial 
TABLE 1: Index system of Chinese industry-university-research collaborative innovation system evolution.

\begin{tabular}{ll}
\hline Variable & Indicators \\
\hline \multirow{2}{*}{ Innovation capacity } & Growth in the number of patent applications (\%) \\
& Enterprise market share (\%) \\
& Ratio of new products to total enterprise products (\%) \\
& Success rate of innovation projects (\%) \\
& New product sales margins (\%) \\
\hline & Amount of money enterprises invest in product development (ten thousand RMB) \\
& Enterprises' business loan growth (\%) \\
R\&D configuration & Growth of R\&D funds of universities and research institutes from corporate (\%) \\
& Total number of R\&D institutions of enterprises (set) \\
& The proportion of investment growth in R\&D personnel (\%) \\
\hline Knowledge transfer & Productivity of high quality achievements (\%) \\
& Number of high level articles of partner universities (piece) \\
& Number of staff entering into enterprises from universities (person) \\
& Number of patents enterprises purchased every year (set) \\
& Number of universities in industry-university-research cooperation (set) \\
\hline
\end{tabular}

TABLE 2: Parameter value of Chinese industry-university-research collaborative innovation system evolution from 2005 to 2014 .

\begin{tabular}{cccc}
\hline Year & $\alpha_{1}$ & $\beta_{1}$ & $\gamma_{1}$ \\
\hline 2005 & 0.0256 & 0.7732 & 0.8422 \\
2006 & 0.0385 & 0.7985 & 0.8974 \\
2007 & 0.0418 & 0.8279 & 0.9361 \\
2008 & 0.0477 & 0.8741 & 0.9713 \\
2009 & 0.0512 & 0.9278 & 1.0284 \\
2010 & 0.0536 & 0.9516 & 1.2947 \\
2011 & 0.0744 & 1.0479 & 1.5820 \\
2012 & 0.0892 & 1.2346 & 1.8046 \\
2013 & 0.0986 & 1.8512 & 1.9239 \\
2014 & 0.1032 & 2.2017 & 2.1158 \\
\hline
\end{tabular}

TABLE 3: Parameter value of evolution model.

\begin{tabular}{lccc}
\hline Variable & $\alpha$ & $\beta$ & $\gamma$ \\
\hline$n_{1}$ & 0.0624 & 1.1489 & 1.3396 \\
$n_{2}$ & 0.1475 & 1.5267 & 1.9464 \\
$n_{3}$ & 0.4587 & 1.2982 & 1.3983 \\
\hline
\end{tabular}

conditions, the resulting response curves are different, representing the new steady state. Substituting the relevant data values into the Jacobian matrix, we used MATLAB software to simulate the evolution curves of the 3 variables $n_{1}, n_{2}, n_{3}$. When the initial values of $n_{1}, n_{2}, n_{3}$ are different, the output of the system response curve is as shown in Figures 2-8:

Figure 2 illustrates that, at a high setting of innovation in the Chinese IURCI system, collaborative innovation system variables show a rapidly increasing trend in a short period. Among them, the simulation curve of innovation capacity appears as a slowly rising trend after the first drop; we believe the reason for this phenomenon is that, in the real situation of limited resources, the original basis for the innovation capacity of the Chinese IURCI system needs to quickly adjust

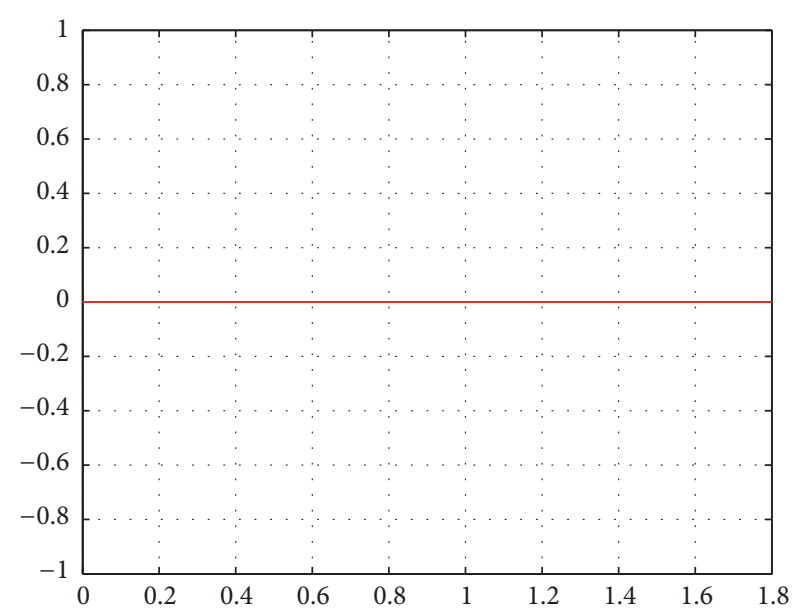

FIGURE 1: Steady state of industry-university-research collaborative innovation system (0 input).

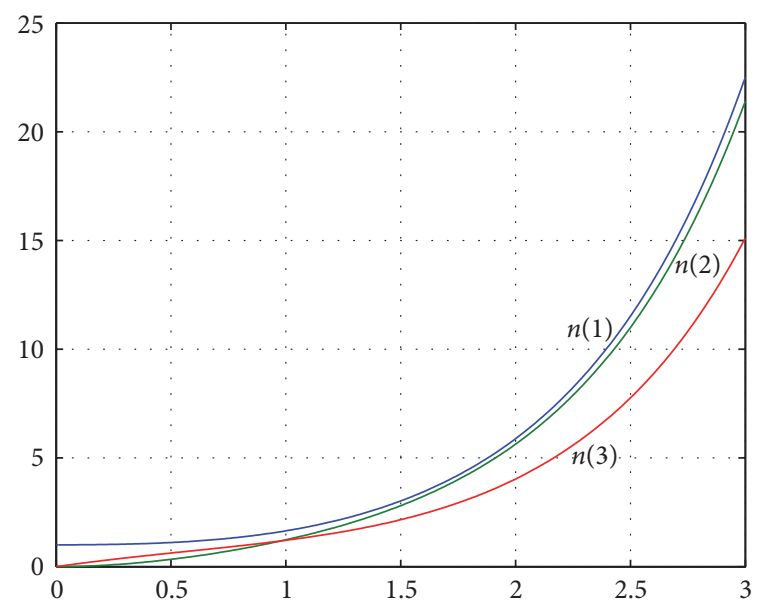

FIGURE 2: Evolution curve of variables when the initial state set as $[1,0,0]$. 


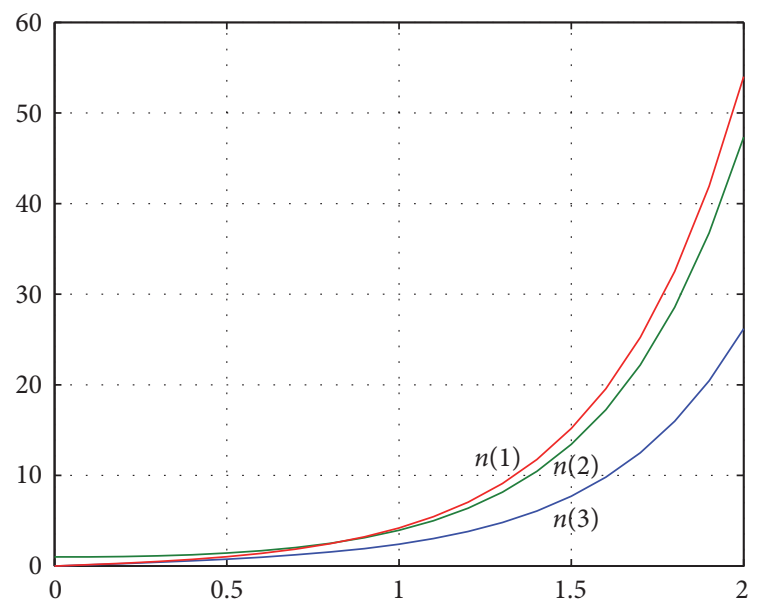

FIGURE 3: Evolution curve of variables when the initial state set as $[0,1,0]$.

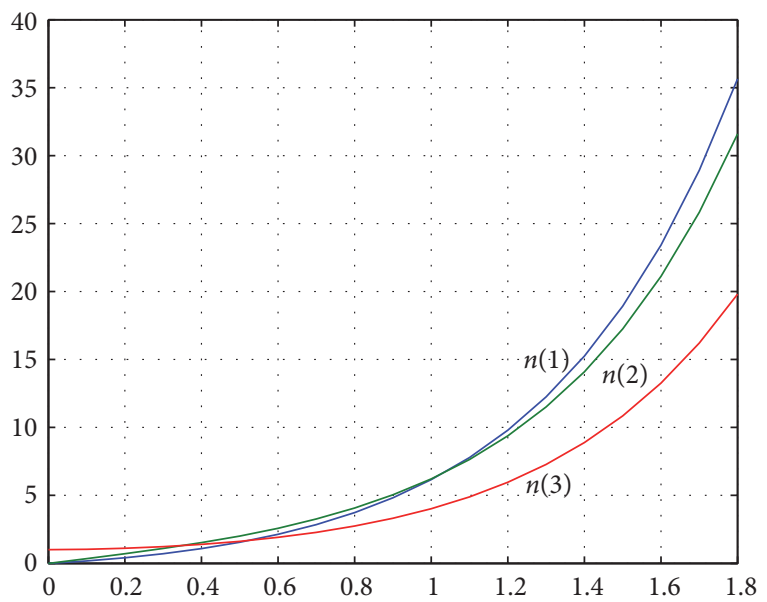

FIGURE 4: Evolution curve of variables when the initial state set as $[0,0,1]$.

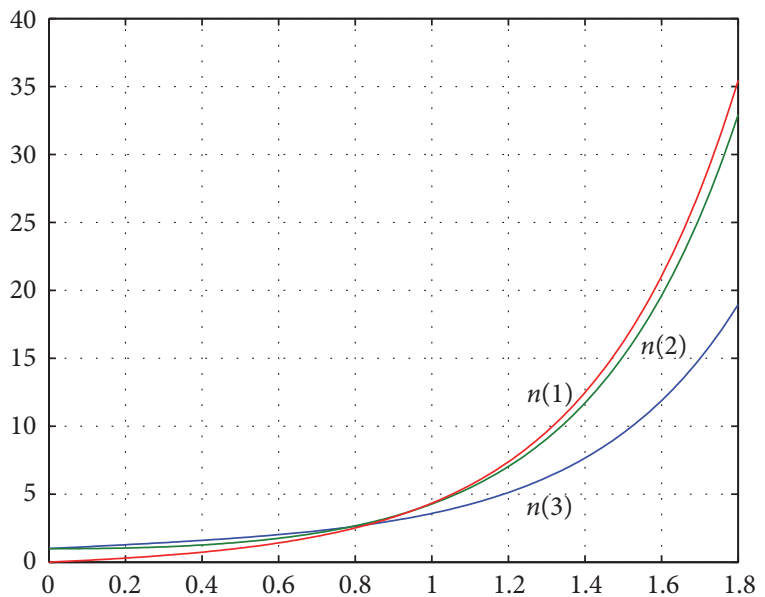

FIGURE 5: Evolution curve of variables when the initial state set as $[0,1,1]$.

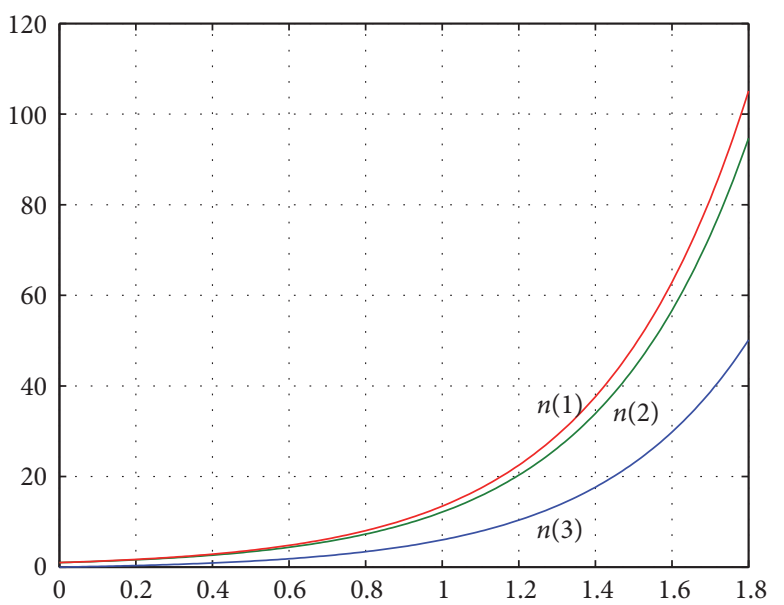

FIGURE 6: Evolution curve of variables when the initial state set as $[1,1,0]$.

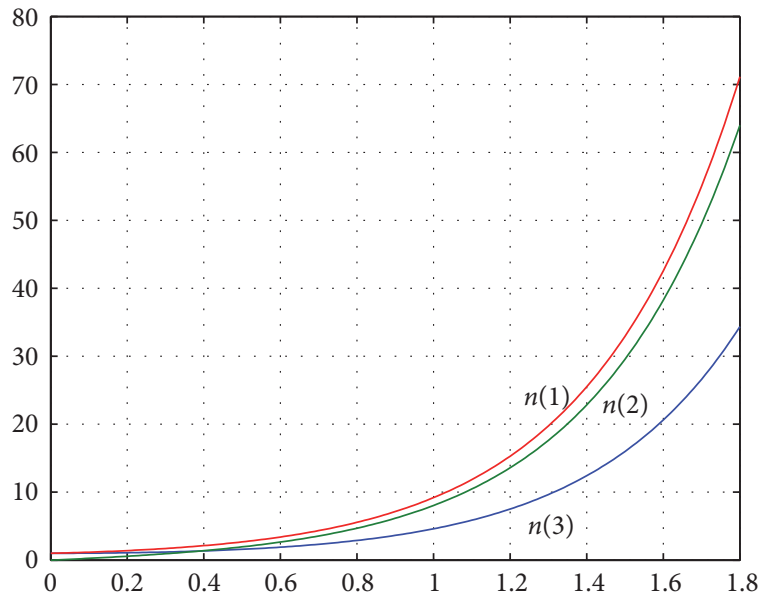

FIgURE 7: Evolution curve of variables when the initial state set as $[1,0,1]$.

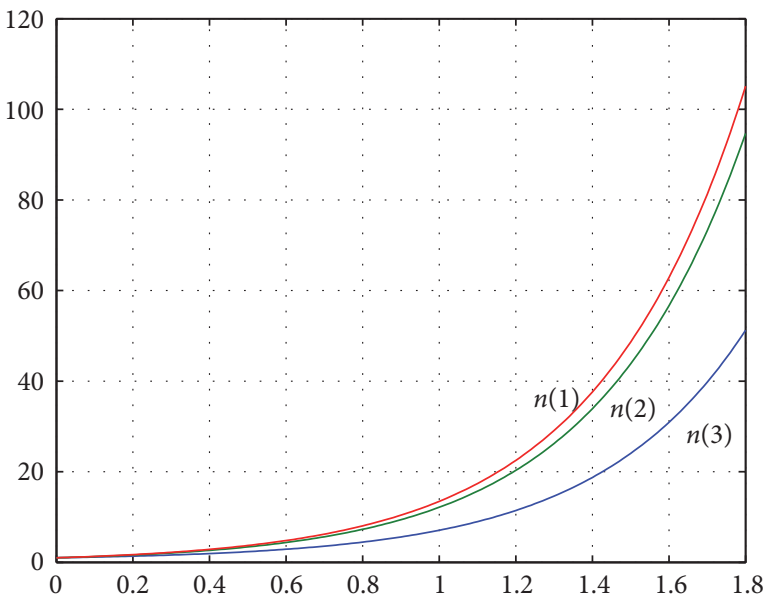

FIGURE 8: Evolution curve of variables when the initial state set as $[1,1,1]$. 
to market demand and devote effort towards knowledge transfer activities, resulting in the short-term declining trend of innovation capacity due to output of resources. In the long term, due to the fact that the knowledge base of the IURCI system has been stabilized, a complementary relationship between innovation capacity and R\&D configuration is produced, resulting in a faster innovation capability upgrade. This indicates that since the Chinese IURCI system lags behind that of developed countries, the ability to innovate and the evolution of a collaborative innovation system will help to improve targeting of the R\&D configuration for businesses, universities, and research institutes and can also enhance promotion of knowledge transfer capability. But, fundamentally, the Chinese IURCI system more likely depends on the innovation capacity for breakthrough innovations and on comprehensively promoting the industrialization of acquired knowledge. In order to foster and enhance the innovative capability, the Chinese IURCI system not only needs to more efficiently allocate limited resources, by means of knowledge transfer, but also should provide enterprises with the highvalue heterogeneity knowledge created by universities and research institutions, form a sustained and stable directional flow of knowledge, establish a good feedback path, form complementary advantages, and establish risk sharing, resulting in mutual benefit and a win-win coinnovation situation. Meanwhile, long-term interactions between universities and research institutions and enterprises also contribute to the mutual fit of collaborative innovation between variables; thus knowledge of different attributes can interact to achieve an optimal combination of knowledge resources, achieve knowledge innovation and added value, and ultimately produce the desired collaborative innovation effect, which will enhance the overall competitive advantages of university and industry.

Figure 3 shows that when the systemic R\&D configuration is set as 1 , that is, if the Chinese IURCI has a more comprehensive and adequate $\mathrm{R} \& \mathrm{D}$ configuration, each variable in the same period has increased significantly, and the evolution speed of innovation capacity is closer to that of the R\&D configuration; then the evolution speed of knowledge transfer is relatively slow, being increased only from 0 to about 5.2. Meanwhile, we compared Figures 2 and 3 and found that the evolution curve of knowledge transfer has always been lower than that of innovation capacity and R\&D configuration; this phenomenon reveals the fact that, in the evolution process of the Chinese IURCI system, the contribution of knowledge transfer to the evolution of innovative capacity is low, which explains why the influence degree of knowledge transfer on Chinese IURCI system evolution is significantly low. Thus companies can understand that, in the current external environment and policy context, too much dependence on knowledge transfer from universities and research institutions may not achieve the best collaborative innovation strategy. Therefore, under the current circumstances, the Chinese IURCI system mainly considers knowledge transfer as an assistance mode for collaborative innovation and new knowledge access and focuses on enhancing their own innovation capacity and the reasonability of the R\&D configuration. Further, as the Chinese IURCI system continues to evolve, universities and research institutions have clearer requirements for the distribution of benefits, and, coupled with a gradual improvement of the intellectual property system, this could lead to a longer cycle of knowledge transfer between enterprises, universities, and research institutions. At this time, collaborative innovation and research will be more inclined to be aided by innovation capability improvement, so that the focus on knowledge transfer is declining. It can be seen that, in the Chinese IURCI system, enhancing the innovation capacity is more important and knowledge transfer has not played its due role, which shows that the Chinese IURCI system has issues around weak knowledge transfer, inadequate trust and cooperation mechanisms between enterprises and universities as well as research institutions, and insufficient knowledge acquisition by enterprises from universities and research institutions.

Figure 4 illustrates, in the context of a lack of innovation capacity and incomplete R\&D configuration, that if the Chinese IURCI system was to have more prominent knowledge transfer ability, then knowledge transfer can to some extent contribute to the evolution of collaborative innovation. From Figures 3 and 4, it can be seen that whether we set the $\mathrm{R} \& \mathrm{D}$ configuration as 1 and the knowledge transfer as 0 , or the knowledge transfer as 1 and the R\&D configuration as 0 , as long as these 2 variables have an initial value, they will encourage the innovation capacity in the Chinese IURCI system to improve rapidly. It means that, in this context, innovation capacity is highly correlated with $R \& D$ configuration and knowledge transfer in the Chinese IURCI system. Enhancing knowledge transfer capability can help businesses more efficiently and in a more targeted way obtain knowledge that universities and research institutions create and promulgate, which can enhance the speed of knowledge commercialization and help IURCI to achieve high performance, thus strengthening the Chinese IUR union by maintaining internal synergies between knowledge supply and knowledge application. This has a positive impact on promoting collaborative innovation activities and enhancing the confidence of IUR cooperation. At the same time, compared to Figures 2 and 3, it can be seen that, although more prominent knowledge transfer can speed up innovation capacity, the enhancing effectiveness is still lower than that of R\&D configuration. The reason may be that knowledge transfer from universities and research institutions is the main way to promote Chinese IURCI system evolution, since the basis of innovation and scientific and technical human capital on the part of enterprises are poor, knowledge input and support of the collaborative innovation system are totally dependent on knowledge transfer from the universities and research institutions side. However, due to the nature of knowledge transfer, there is a certain lag, so, in the absence of appropriate $R \& D$ configuration support, the promotion of innovation capability from universities and research institutions is not obvious, so the Chinese IURCI requires a longer cooperation period.

Figure 5 shows that when R\&D configuration and knowledge transfer are more prominent in the Chinese IURCI system, the increase in innovation capacity is more obvious than the results of Figures 2, 3, and 4. This demonstrates that $\mathrm{R} \& \mathrm{D}$ configuration and knowledge transfer coaffect 
the evolution of innovation capacity in the Chinese IURCI system; that is, there are significant positive feedback effects among the 3 variables, which mutually promote each other. It means that, at such time, as the Chinese IURCI system has some input resources and knowledge transfer capability, these factors will be beneficial to rapidly increasing the collaborative innovation knowledge level and innovation capacity, thus improving collaborative innovation performance. We believe that the reasons for this may be twofold: on the one hand, more effective knowledge transfer between corporations and universities as well as research institutions promotes knowledge industrialization, so the innovation capability of enterprises quickly upgrades in the process of repeated practice and constant learning, which to a certain extent promotes IURCI performance. On the other hand, rational and targeted R\&D configuration allows universities and research institutions, under the premise of having a stable knowledge base, to reduce the time delay of knowledge transfer in the process of collaborative innovation and put part of their resources into the process of promotion of knowledge transfer capacity, thereby achieving a mutual fit with $R \& D$ configuration. It should be noted that, in the initial stage of simulation, namely, the early period of Chinese IURCI practice, favorable Chinese government policies and attention to IURCI could promote the speed of knowledge industrialization. But knowledge transfer from universities and research institutions is subject to adverse factors in the cooperation run-in period and may produce a situation of no improvement. With the in-depth evolution of the IURCI system, cooperation between businesses and universities and research institutions can mature, so that universities and research institutions have clearer ideas about industry needs and more accurately provide the necessary knowledge to enterprises for knowledge industrialization. Universities and research institutions will also benefit from collaborative innovation as they better understand industry technology needs and market demand, allowing them to optimize their knowledge structure, thus enhancing the IURCI performance.

Figure 6 illustrates that, in the evolution process of IURCI that relies on innovation capacity and R\&D configuration, continuously increasing R\&D configuration will make evolution of innovation capacity significantly faster. At the same time, compared to Figure 5, it can be found that, in the evolution of the Chinese IURCI system, if $R \& D$ configuration has an initial value, to enhance the IURCI performance, enterprises must operate on the basis of continuously developing their R\&D configuration, obtaining as much as possible valuable heterogeneity knowledge from universities and research institutions, and universities and research institutions also need to enhance their abilities to transfer knowledge and fit the production needs of industry in order to obtain more significant innovation performance. In addition, this case also shows that although there may be differences in their abilities to innovate, for those enterprises that lack the ability to innovate, the input of external resources and the gain of valuable knowledge by way of knowledge transfer may change the current disadvantage and help them achieve rapid growth.
Figures 5 and 6 both show that the innovation capacity and $R \& D$ configuration of the Chinese IURCI system can in a short period of time produce significant synergies and promote each other, indicating that China's current IURCI development still requires a lot of resources investment as the primary means to enhance innovation capability. But when $\mathrm{R} \& \mathrm{D}$ configuration is high, the result of innovation capacity evolution [38] is lower than that when knowledge transfer is relatively high, which gives high values of innovation evolution [42]. On the one hand, this indicates that, in the current process of IURCI in China, the universities and research institutions side creates and sends high-value heterogeneity knowledge, which has a fundamental role in promoting innovation capacity. On the other hand, to a certain extent, this confirms that if Chinese universities and research centers could face knowledge-oriented industrial demand, enterprises could accurately identify the market value of accepted knowledge, change the discrepancy that exists between technology supply and technology demand, and thereby reduce its dependency on R\&D configuration, while, at the same time, shortening the innovation cycle and avoiding the issues such as information asymmetry and transaction costs that may arise during collaborative innovation [42-44].

Figure 7 illustrates that when innovation capacity and knowledge transfer are more prominent and R\&D configuration is lower, variables of the Chinese IURCI could promote each other by interaction, but the growth rate is relatively small, indicating that relying solely on knowledge transfer to promote innovation capacity is not effective. On the one hand, this confirmed that the type of knowledge produced by Chinese universities and research institutions must have applicability to be promoted to companies for industrialization. On the other hand, this maybe results from enterprises having an inadequate knowledge absorptive capacity. Meanwhile, from Figures 7, 5, and 6, it can be found that if the R\&D configuration of the Chinese IURCI system is poor, then there will be a very significant impact on the ability to enhance knowledge transfer speed. The possible reasons are that when $\mathrm{R} \& \mathrm{D}$ configuration is not enough, the Chinese IURCI system is already in the process of tight resource allocation, and it is bound to devote more resources into promotion activities that create a high-value heterogeneity innovation capacity, and it therefore lacks the resources to facilitate knowledge transfer within the system. Correspondingly, if resources are relatively abundant, enterprises must allow for a bottleneck phenomenon in enhancing innovation capacity or accept greater risks in innovative activity and may assign the resources originally devoted to innovative ability to universities and research institutions, supporting the knowledge transfer willingness of universities and research institutions and thus enhancing knowledge transfer for collaborative innovation. In this case, the evolution curve of knowledge transfer will be more significant.

Figure 8 clearly shows that when the innovation capacity of the Chinese IURCI system is more prominent, $R \& D$ configuration is more targeted, knowledge transfer capability is better, and the 3 state variables of collaborative innovation 
show rapid and steady evolution. Among them, the growth rate of innovation capability is the most significant, so that after a new stable state is established, knowledge transfer and $\mathrm{R} \& \mathrm{D}$ configuration both can have a more substantial growth effect on innovation capability. This means that, in order to achieve the objective of significantly improved collaborative innovation performance, the Chinese IURCI system must adhere to long-term independent innovation activities and in addition must maintain and increase the basic R\&D configuration, constantly improve knowledge transfer capacity, and more effectively and pertinently send to enterprises the complementary knowledge that universities and research institutions own. With advances in IURCI, this approach may bring 2 advantages for enterprises, universities, and research institutions involved in Chinese IURCI, but, from a business perspective, at present, the awareness of Chinese enterprises to acquire complementary knowledge in an IUR-coordinated manner is poor, and so initiative is very low. If enterprises realize that, on the basis of improving R\&D configuration, they can obtain complementary research achievement by making use of knowledge transfer form; then this will greatly increase the willingness of Chinese enterprises to participate in IURCI, thereby using new technology, developing new products, and approaching university $\mathrm{R} \& \mathrm{D}$ personnel, which is beneficial to building a trust-based cooperation mechanism between enterprises and universities as well as research institutions [45-48]. From the perspective of Chinese universities and research institutes in the process of knowledge creation, the biggest drawback is that new knowledge cannot be applied to production practice; that is, universities and research institutions pay too much attention to academic value. With periodic IURCI, universities and research institutions can not only receive financial support from the business, according to the needs of the business to carry out research activities but also fully explore new research areas, which will also play a positive role in promoting more academic achievements $[49,50]$.

From observing Figures 3-8 we found that, in the current Chinese IURCI process, R\&D configuration always maintains a high degree of positive correlation with innovation capacity. The reasons for this may be that China's current IURCI system is not perfect, and enterprises and universities as well as research institutions are always looking for cooperation modes suitable for both sides. Meanwhile, the process of knowledge transfer itself is relatively slow, and, between Chinese enterprises and universities, there might exist negative factors affecting knowledge transfer speed (such as knowledge flow cost and familiarity running process between staffs), and these factors will result in reduced efficiency of knowledge transfer; therefore growth of knowledge transfer is always slow.

In short, in China's IURCI process, a consistent relationship indeed exists among innovation capability, knowledge transfer, and R\&D configuration. In a higher knowledge transfer and comprehensive R\&D configuration scenario, enterprises can propose more targeted knowledge needs and initially provide financial and material support for universities and research institutions involved in innovation. Universities and research institutions from the strategic level are also concerned about how to establish knowledge R\&D to serve enterprises and, under the premise of integrated resources, establish a balanced benefits distribution, actively carry out scientific and technological achievement transfer, train technology and management personnel required for enterprises, exert collaborative innovation effects by complementary advantages, and thus bring new benefits for both sides.

\section{Conclusion}

By combining methods of game theory and complex science, we studied the evolution of the Chinese IURCI system and interactions among the variables. We used interactions among variables in a collaborative innovation system to "map" the perspective of collaborative innovation evolution and study innovation capacity, R\&D configuration, and knowledge transfer as key elements of collaborative innovation, and, on the basis of establishing a dynamic system evolution model of collaborative innovation, we collected data, simulated, discussed interactions among the variables in the process of Chinese IURCI, and analyzed principles of collaborative innovation. We mainly obtained the following conclusions:

(1) In the evolution of the Chinese IURCI system, innovation capacity and knowledge transfer are dependent on $\mathrm{R} \& \mathrm{D}$ configuration, and innovation capability is highly positively correlated with R\&D configuration. The higher the target and investment level of R\&D configuration, the faster the evolution of innovation capacity and knowledge transfer. It is noted that currently Chinese IURCI development is using a lot of resource investment as its main factor. Innovation capacity has become the key variable to promote collaborative innovation system evolution.

(2) Strong knowledge transfer capability can accelerate the evolution speed of innovation capacity, but overall knowledge transfer remains at a relatively stable evolution state and does not change with evolution of collaborative innovation. This explains that, in the evolution process of China's current IURCI system, virtuous cooperation mechanisms based on trust between enterprises and universities as well as research institutions are lacking. Universities and research institutions also pay more attention to the academic value of knowledge, leading to insufficient contribution of knowledge transfer to knowledge industrialization by enterprises and reduced collaborative innovation system evolution.

(3) In a relatively balanced state of innovation capacity, $\mathrm{R} \& \mathrm{D}$ configuration, and knowledge transfer, the faster the evolution speed of Chinese IURCI systems, the higher the stability. This shows that the Chinese IURCI system must adhere to long-term independent innovation, and, on the basis of maintaining and improving R\&D configuration, constantly improve internal knowledge transfer capability.

Compared with early research, this article has 3 main findings: first, we chose China as a developing country with rapid economic growth, used a dynamic perspective, analyzed the evolution mechanism of the Chinese IURCI system, and demonstrated the interactions among variables of the collaborative innovation system. Secondly, we learned from 
the macroinnovation system theory, the meso-Triple Helix Model, and microopen organization innovation theory, separated the components of the IURCI system, and confirmed contribution degrees of different variables to collaborative innovation system evolution, with particular emphasis on different initial values. Our rationale of analyzing 3 variables with different evolutionary trends not only theoretically contributed to enrich the innovative theory system but also made developmental strategies for Chinese enterprises and universities as well as research institutions and provided an optimized direction to enhance collaborative innovation performance. Thirdly, in this study, we considered IURCI as a complex system with dynamic evolution and, by analysis of systemic evolution and cooperative status among variables, we effectively revealed some issues existing in the current Chinese IURCI.

This study made 2 contributions to studies of IURCI based on resources and knowledge management theory: first, this study overcame the disadvantage of only using transaction cost theory and organization management theory to analyze comprehensiveness and complexity of collaborative innovation. The research framework and methodology proposed in this study will help researchers deal with challenges so that, in a dynamic environment, the synergistic effect of different variables of the IURCI system results in complexity of collaborative innovative evolution. Secondly, the method chosen for this study is different from past collaborative innovation research processes that were narrower and divided by limited dimensions. We started from the variables that determine the IURCI system, established a nonlinear model based on the interactions among variables, confirmed the impact level of different state variables on collaborative innovation, and defined the mechanism of interactions between state variables and evolution trend. The use of this new method to obtain new conclusions is necessary for further research on collaborative innovation.

This study is also of great practical implication. Based on 10 years of data published by Chinese government, interactions and evolution trend among innovation capacity, $\mathrm{R} \& \mathrm{D}$ configuration and knowledge transfer in different contexts are given by means of simulation, thus specifying existing problems in China's IURCI system. Conclusions obtained are beneficial in helping enterprises managers take measures to promote knowledge absorption, in helping universities and research institutions clarify knowledge transfer dilemma in certain knowledge demand condition, and helping government form proper resource allocation mode. Therefore, the new conceptualization provides a useful guide for managers to make rational knowledge developing strategy, for universities and research institutes to diagnose barriers in knowledge transfer, and for government to take necessary policy-making.

Selecting data from different countries to conduct comparisons and discuss classification is the main research direction in the future. Because the framework proposed in this study can be used in many fields, this study plays a guiding role to some extent in practical sample collection and analysis when trying to select future strategic alliances, practice communities, and other subjects. Meanwhile, we hoped to bring the phenomenon of knowledge diffusion into research and, by improving existing models, achieve a complete interpretation of IURCI issues on aspects of theory and practice, thus making research more focused.

\section{Conflicts of Interest}

The authors declare no conflicts of interest of regarding the publication of this paper.

\section{Acknowledgments}

This study is supported by the National Natural Science Foundation of China (71602041, 71602042 and 71301065); National Social Science Key Project of China (ID: 14AGL004); China Postdoctoral Science Foundation (2015M570299 and 2016M590605); Fundamental Research Funds for the Central Universities of China (ID: HEUCF150901); Postdoctoral Science Foundation of Heilongjiang Province (LBH-15075); and Postdoctoral Science Foundation of Jiangxi Province (2016KY27).

\section{References}

[1] O. W. Maietta, "Determinants of university-firm R\&D collaboration and its impact on innovation: a perspective from a lowtech industry," Research Policy, vol. 44, no. 7, pp. 1341-1359, 2015.

[2] M. D. Santoro and P. E. Bierly III, "Facilitators of knowledge transfer in university-industry collaborations: a knowledgebased perspective," IEEE Transactions on Engineering Management, vol. 53, no. 4, pp. 495-507, 2006.

[3] O. Al-Tabbaa and S. Ankrah, "Social capital to facilitate "engineered" university-industry collaboration for technology transfer: a dynamic perspective," Technological Forecasting and Social Change, vol. 104, pp. 1-15, 2016.

[4] A. I. Canhoto, S. Quinton, P. Jackson, and S. Dibb, "The co-production of value in digital, university-industry R\&D collaborative projects," Industrial Marketing Management, vol. 56, pp. 86-96, 2016.

[5] S. Arvanitis, U. Kubli, and M. Woerter, "University-industry knowledge and technology transfer in Switzerland: what university scientists think about co-operation with private enterprises," Research Policy, vol. 37, no. 10, pp. 1865-1883, 2008.

[6] M. Perkmann and K. Walsh, "University-industry relationships and open innovation: towards a research agenda," International Journal of Management Reviews, vol. 9, no. 4, pp. 259-280, 2007.

[7] K. Koschatzky, "Networking and knowledge transfer between research and industry in transition countries: empirical evidence from the Slovenian innovation system," The Journal of Technology Transfer, vol. 27, no. 1, pp. 27-38, 2002.

[8] A. Inzelt, "The evolution of university-industry-government relationships during transition," Research Policy, vol. 33, no. 6-7, pp. 975-995, 2004.

[9] N. Yumusak, I. Ozcelik, M. Iskefiyeli, M. F. Adak, and T. Kırktepeli, "University industry linkage projects management system," Procedia-Social and Behavioral Sciences, vol. 174, pp. 3254-3259, 2015.

[10] J. Zhao, X. Xi, and S. Yi, "Resource allocation under a strategic alliance: how a cooperative network with knowledge flow spurs 
co-evolution," Knowledge-Based Systems, vol. 89, pp. 497-508, 2015.

[11] J. Berbegal-Mirabent, J. L. Sánchez García, and D. E. RibeiroSoriano, "University-industry partnerships for the provision of R\&D services," Journal of Business Research, vol. 68, no. 7, pp. 1407-1413, 2015.

[12] R. Fontana, A. Geuna, and M. Matt, "Factors affecting university-industry R and D projects: the importance of searching, screening and signalling," Research Policy, vol. 35, no. 2, pp. 309-323, 2006.

[13] S.-H. Chen, M.-H. Huang, and D.-Z. Chen, "Driving factors of external funding and funding effects on academic innovation performance in university-industry-government linkages," Scientometrics, vol. 94, no. 3, pp. 1077-1098, 2013.

[14] B. A. Lundvall, National Innovation System: Toward a Theory of Innovation and Interactive Learning, Pinter, London, UK, 1992.

[15] P. Cooke, M. G. Uranga, and G. Etxebarria, "Regional systems of innovation: an evolutionary perspective," Environment and Planning A, vol. 30, no. 9, pp. 1563-1584, 1998.

[16] A. K. W. Lau and W. Lo, "Regional innovation system, absorptive capacity and innovation performance: an empirical study," Technological Forecasting and Social Change, vol. 92, pp. 99-114, 2015.

[17] I. A. Ivanova and L. Leydesdorff, "Rotational symmetry and the transformation of innovation systems in a Triple Helix of university-industry-government relations," Technological Forecasting and Social Change, vol. 86, pp. 143-156, 2014.

[18] I. A. Ivanova and L. Leydesdorff, "Knowledge-generating efficiency in innovation systems: the acceleration of technological paradigm changes with increasing complexity," Technological Forecasting and Social Change, vol. 96, pp. 254-265, 2015.

[19] L. Leydesdorff and M. Meyer, "Triple Helix indicators of knowledge-based innovation systems: introduction to the special issue," Research Policy, vol. 35, no. 10, pp. 1441-1449, 2006.

[20] H. Etzkowitz and L. Leydesdorff, "The triple helix Universityindustry government relations: a laboratory for knowledge based economic development," EASSR Review, vol. 14, no. 1, pp. 11-19, 1995.

[21] H. W. Chesbrough, Open Innovation: The New Imperative for Creating and Profiting from Technology, Harvard Business Press, 2003.

[22] J. West and K. R. Lakhani, "Getting clear about communities in open innovation," Industry and Innovation, vol. 15, no. 2, pp. 223-231, 2008.

[23] A. Draghici, C. Baban, M. Gogan, and L. Ivascu, "A knowledge management approach for the university-industry collaboration in open innovation," Procedia Economics and Finance, vol. 23, pp. 23-32, 2015.

[24] L. Striukova and T. Rayna, "University-industry knowledge exchange: an exploratory study of Open Innovation in UK universities," European Journal of Innovation Management, vol. 18, no. 4, pp. 471-492, 2015.

[25] G. George, S. A. Zahra, and D. R. Wood Jr., "The effects of business-university alliances on innovative output and financial performance: a study of publicly traded biotechnology companies," Journal of Business Venturing, vol. 17, no. 6, pp. 577-609, 2002.

[26] K. Laursen and A. Salter, "Open for innovation: the role of openness in explaining innovation performance among U.K. manufacturing firms," Strategic Management Journal, vol. 27, no. 2, pp. 131-150, 2006.
[27] A. Winkelbach and A. Walter, "Complex technological knowledge and value creation in science-to-industry technology transfer projects: the moderating effect of absorptive capacity," Industrial Marketing Management, vol. 47, pp. 98-108, 2015.

[28] Y.-J. Chen, Y.-M. Chen, and M.-S. Wu, "An empirical knowledge management framework for professional virtual community in knowledge-intensive service industries," Expert Systems with Applications, vol. 39, no. 18, pp. 13135-13147, 2012.

[29] M. C. J. Caniëls and B. Verspagen, "Barriers to knowledge spillovers and regional convergence in an evolutionary model," Journal of Evolutionary Economics, vol. 11, no. 3, pp. 307-329, 2001.

[30] M.-C. Hu, "Knowledge flows and innovation capability: the patenting trajectory of Taiwan's thin film transistor-liquid crystal display industry," Technological Forecasting and Social Change, vol. 75, no. 9, pp. 1423-1438, 2008.

[31] J. Bercovitz and M. Feldmann, "Entpreprenerial universities and technology transfer: a conceptual framework for understanding knowledge-based economic development," Journal of Technology Transfer, vol. 31, no. 1, pp. 175-188, 2006.

[32] A. Bonaccorsi and A. Piccaluga, "A theoretical framework for the evaluation of university-industry relationships," R\&D Management, vol. 24, no. 3, pp. 229-247, 1994.

[33] E. G. Carayannis, J. Alexander, and A. Ioannidis, "Leveraging knowledge, learning, and innovation in forming strategic government-university-industry (GUI) R\&D partnerships in the US, Germany, and France," Technovation, vol. 20, no. 9, pp. 477-488, 2000.

[34] L. Anatan, "Conceptual issues in university to industry knowledge transfer studies: a literature review," Procedia-Social and Behavioral Sciences, vol. 211, pp. 711-717, 2015.

[35] H. W. Chesbrough, W. Vanhaverbeke, and J. West, Open Innovation: Researching a New Paradigm, Oxford University Press, Oxford, UK, 2008.

[36] Y. Baba, N. Shichijo, and S. R. Sedita, "How do collaborations with universities affect firms' innovative performance? The role of 'Pasteur scientists' in the advanced materials field," Research Policy, vol. 38, no. 5, pp. 756-764, 2009.

[37] H. Haken, The Science of Structure: Synergetics, Van Nostrand Reinhold, Grantham, UK, 1981.

[38] J. L. Kuang, P. A. Meehan, and A. Y. Leung, "Suppressing chaos via Lyapunov-Krasovskii's method," Chaos, Solitons \& Fractals, vol. 27, no. 5, pp. 1408-1414, 2006.

[39] G. A. Anastassiou, "Distributional Taylor formula," Nonlinear Analysis. Theory, Methods \& Applications, vol. 70, no. 9, pp. 3195-3202, 2009.

[40] Y. Khan, H. Vázquez-Leal, and N. Faraz, "An auxiliary parameter method using Adomian polynomials and Laplace transformation for nonlinear differential equations," Applied Mathematical Modelling, vol. 37, no. 5, pp. 2702-2708, 2013.

[41] S. F. AL-Azzawi, "Stability and bifurcation of pan chaotic system by using Routh-Hurwitz and Gardan methods," Applied Mathematics and Computation, vol. 219, no. 3, pp. 1144-1152, 2012.

[42] S. Owen and A. Yawson, "Information asymmetry and international strategic alliances," Journal of Banking and Finance, vol. 37, no. 10, pp. 3890-3903, 2013.

[43] R. A. Jensen, J. G. Thursby, and M. C. Thursby, "Disclosure and licensing of University inventions," International Journal of Industrial Organization, vol. 21, no. 9, pp. 1271-1300, 2003. 
[44] X. Gao, X. Guo, and J. Guan, "An analysis of the patenting activities and collaboration among industry-universityresearch institutes in the Chinese ICT sector," Scientometrics, vol. 98, no. 1, pp. 247-263, 2014.

[45] Y. S. Lee, ““Technology transfer” and the research university: a search for the boundaries of university-industry collaboration," Research Policy, vol. 25, no. 6, pp. 843-863, 1996.

[46] M. Hemmert, L. Bstieler, and H. Okamuro, "Bridging the cultural divide: trust formation in university-industry research collaborations in the US, Japan, and South Korea," Technovation, vol. 34, no. 10, pp. 605-616, 2014.

[47] M. D. Santoro and P. A. Saparito, "The firm's trust in its university partner as a key mediator in advancing knowledge and new technologies," IEEE Transactions on Engineering Management, vol. 50, no. 3, pp. 362-373, 2003.

[48] K. Blomqvist, P. Hurmelinna, and R. Seppänen, "Playing the collaboration game right-balancing trust and contracting," Technovation, vol. 25, no. 5, pp. 497-504, 2005.

[49] A. Geuna and L. J. J. Nesta, "University patenting and its effects on academic research: the emerging European evidence," Research Policy, vol. 35, no. 6, pp. 790-807, 2006.

[50] Y. S. Lee, "The sustainability of university-industry research collaboration: an empirical assessment," Journal of Technology Transfer, vol. 25, no. 2, pp. 111-133, 2000. 


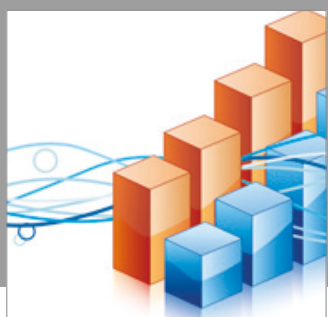

Advances in

Operations Research

vatersals

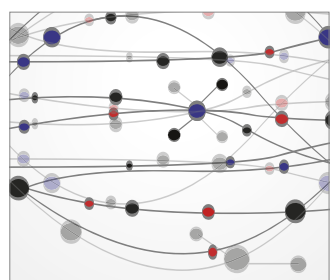

\section{The Scientific} World Journal
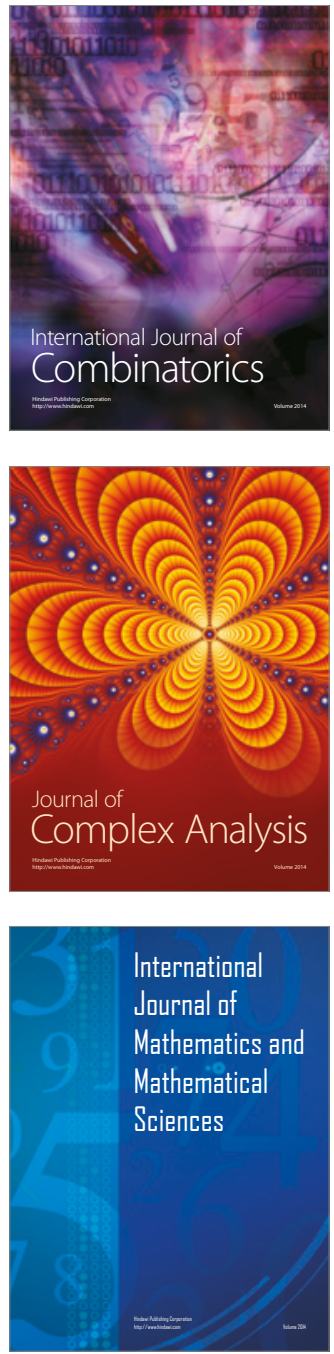
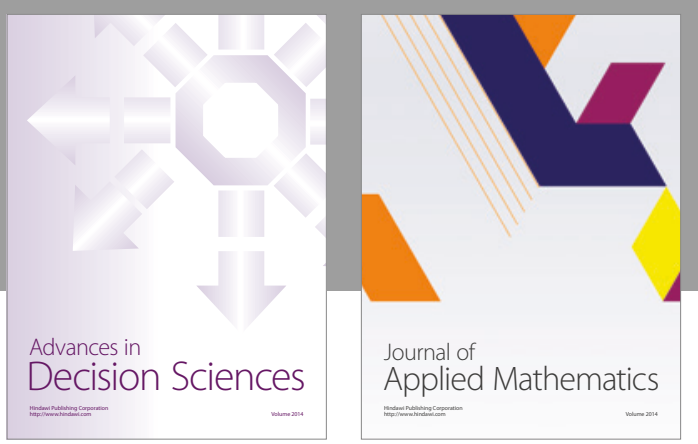

Algebra

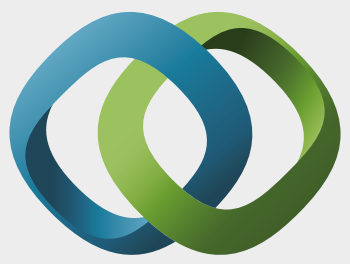

\section{Hindawi}

Submit your manuscripts at

https://www.hindawi.com
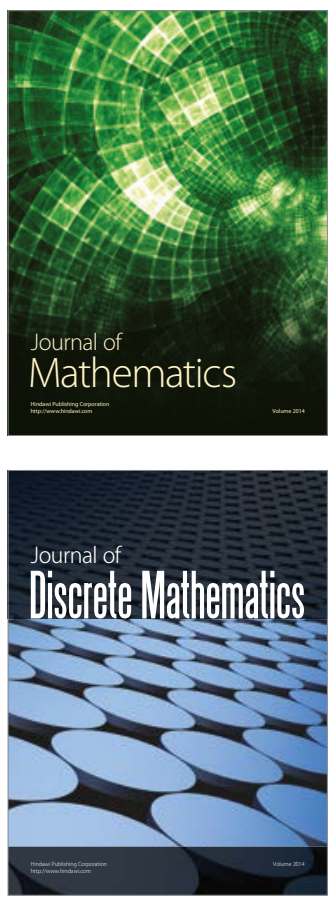

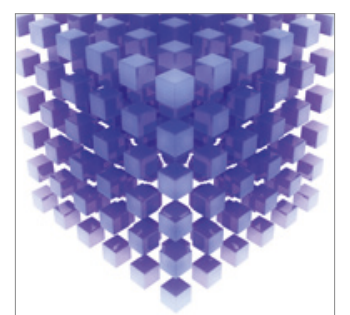

Mathematical Problems in Engineering
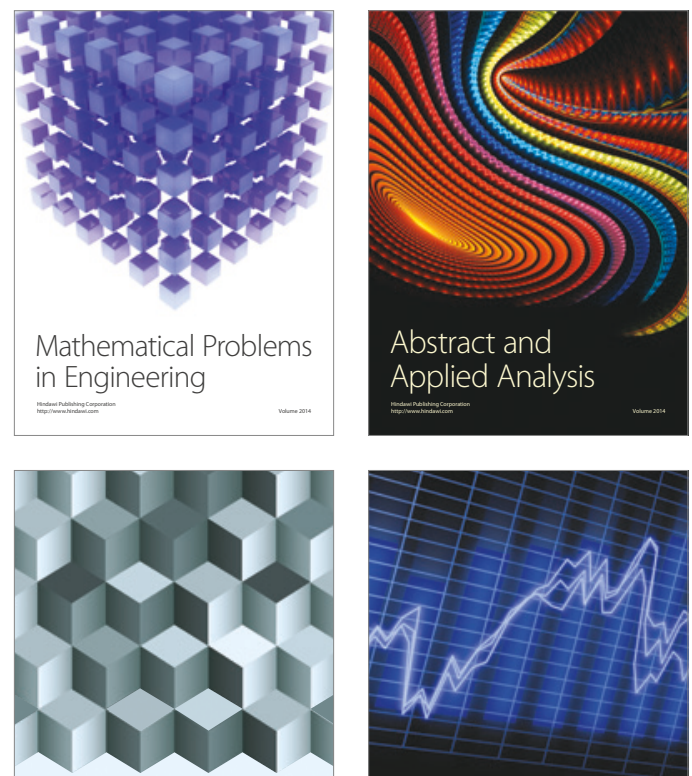

Journal of

Function Spaces

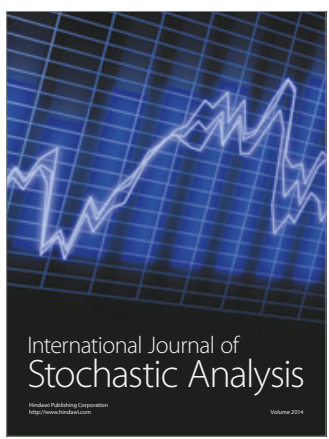

Probability and Statistics
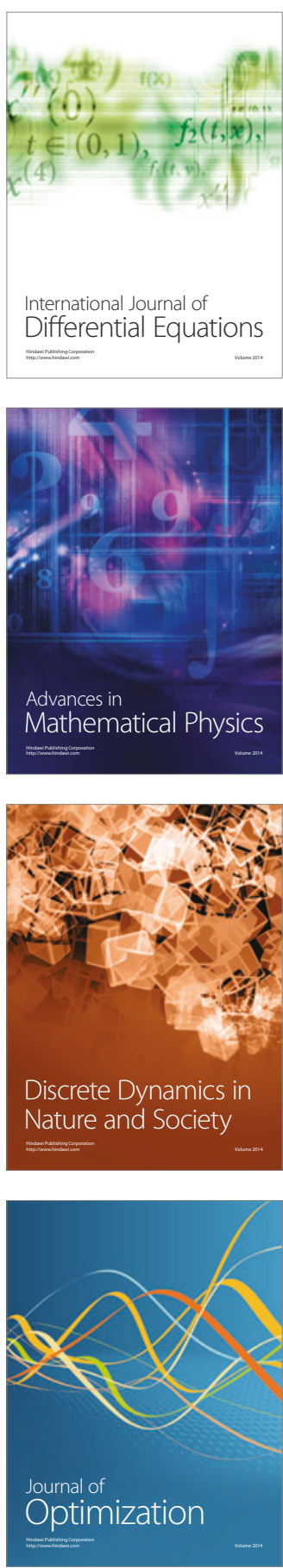